\title{
Peroxidase and Yakriton
}

\section{.Dr. Sh. Yanagawa as the First to Notice Effect of Yakriton} to Intensity Peroxidase; Preliminary Report

By

\author{
Akira Sato \\ (佐 藤彰) \\ From the Department of Pediatrics, Faculty of Medicine, Tohoku \\ University, Sendai. Director: Prof.* A. Sato
}

(Received for publication, July 27, 1953)

At an early time of isolation of yakriton, ${ }^{1)}$ the detoxicating hormone of the liver, Yanagawa ${ }^{2)}$ (now practician in Pediatrics in Tokyo) was studying the effect of the hormone in our Laboratory. Occasionally he tried to test our peroxidase reaction ${ }^{3 \prime}$ on leucocytes of rabbits injected with yakriton, though I thought at that time that he did it rather out of mere curiosity.

Now the peroxidase reaction of rabbit leucocytes is not so intense as in the human case. Yanagawa used to say to me that rabbit peroxidase reaction would be intensified by yakriton injection. At that time I did not pay the slightest attention to these works of his, thinking each time that it must be an accidental result and that the very rabbit he had happened to experiment on must be of strong peroxidase reaction (at that time I had had an only poor experience with yakriton as well as our peroxidase reaction.) I did not even try to see his blood specimens.

A few years after he left our Clinic, our investigation of the Arakawa reaction ${ }^{4}$ had revealed that yakriton injection could make the reaction (normally) positive even without thiamine administration to athiaminotic lactant, because it would mobilize ${ }^{5)}$ the (otherwise unutilized remaining) thiamine within the body. And it was soon found out that also leucocyte peroxidase reaction of rabbit could be intensified (=in fact, normalized) by yakriton alone (even without thiamine).

In other words, thiamine will remove the peroxidase reaction inhibiting substance from blood, and yakriton acts in the same direction due to its thiamine mobilizing effect.

\section{References}

1) Sato, Tohoku J. Exp. Med., 1926, 8, 232.

2) Yanagawa, ibid., 1929, 14, 187.

3) Sato, and Sekiya, ibid., 1926, 7, 111.

4) Arakawa, ibid., 1930, 16, 90.

5) Asakura, ibid., 1932, 19, 269.

* Now Professor emeritus. 